JPDS (Oktober, 2019), Vol. 2, No. 2 h.75-81

E-ISSN: 2655-2469

(c) 2019 Penulis

\title{
KOLABORASI PERGURUAN TINGGI-PEMERINTAH DESA-SWASTA DALAM MENGEMBANGKAN JIWA KEWIRAUSAHAAN PEMUDA DAN WANITA DALAM MEMBANGUN DESA WISATA KEBANGSAAN \\ Sri Untari* \\ sri.untari.fis@um.ac.id
}

Jurusan Hukum dan Kewarganegaraan, Fakultas IImu Sosial, Universitas Negeri Malang

Diterima 23 September 2019, dipublikasikan 31 Oktober 2019

\begin{abstract}
Abstrak
Tujuan pengabdian kepada masyarakat ini adalah: (a) menemukan potensi wisata desa Wonorejo; (b) mengembangkan kerjasama PT-Pemdes-Swasta dalam mengembangkan desa wisata kebangsaan; (c) melaksanakan pendampingan pada karang taruna dan PKK dalam pembuatan cinderamata. Metode pelaksanaan kegiatan dengan menggunakan pendekatan PRA (Partisipation Rural Appraisal)... adapun langkahnya observasi, sosialisasi, fasilitasi, diskusi terfokus, pendampingan dan evaluasi. Hasil kegiatan pengabdian sebagai berikut: (a) potensi desa yang akan dikembangkan adalah potensi wisata alam, yakni Pantai Perengan, (b) kerjasama antara PT yaki UM dengan Pemdes Wonorejo dibuat melalui Nota Kesepahaman, sedangkan dengan swasta tanpa dokumen tertulis; (b) pendampingan PKK, menghasilkan cinderamata sederhana dari koran, dan Karang Taruna dengan kaos sablon yang mengandung ikon "WOKE” Wonorejo Kebangsaan. Berdasarkan hasil pengabdian direkomendasikan pada pemerintah desa untuk membuat desain pengembangan desa wisata kebangsaan, yang dimasukan dalam program rencana pembangunan desa. Bagi UM agar terus melaksanakan pendampingan melalui KKN, PKM dan penelitian serta pengabdian kepada masyarakat secara berkelanjutan dan bagi swasta dalam hal ini pengelola unit Usaha Baluran agar memberi peluang Karang Taruna menjual produksinya dalam baluran display.
\end{abstract}

Kata kunci: Kolaborasi, kewirausahaan. desa, wisata, kebangsaan

\section{PENDAHULUAN}

Desa Wonorejo kecamatan Banyuputih Kabupaten Situbondo telah lama diproyeksikan sebagai "Desa Wisata" yang dikenal dengan desa Wisata kebangsaan, berbagai destinasi mulai digarap oleh desa secara mandiri, karena berdasarkan hasil penelitian Untari (2018) belum ada intervensi dari kabupaten Situbondo dalam hal ini Dinas Pariwisata Daerah. Pada Awalnya para Elit Desa kesulitan mencari identitas wisata desa kebangsaan. Hasil wawancara dengan salah satu tokoh masyarakat yang tidak bersedia disebutkan namanya menyatakan bahwa pada saat mendapat undangan dari Jakarta, mereka ditanyakan oleh Presiden Joko Widodo apakah desa wisata kebangsaan, saat itu mereka tidak dapat menjawab, karena mereka memang tidak mengetahui. Untuk itu telah dilakukan kolaborasi dengan Universitas Negeri Malang (UM) melalui program KKN, PKM-M dan bina desa Fakultas IImu Sosial, merupakan salah satu upaya agar bisa segera merealisasikannya, mengembangkan identitas dari desa wisata kebangsaan. Berdasarkan hasil penelitian dari Untari \& Wantoro, alasan desa ini terpilih sebagai desa kebangsaan, antara lain, kerukunan antar umat beragama, yakni pemeluk agama Islam dan Kristen dan agama lain yang ada yang sangat harmonis, demikian juga keguyuban masyarakat di sana dalam melakukan gotong royong (Untari, 2018; Wantoro, 2018). Hal ini dapat menjadi model kehidupan kebangsaan yang berBhinneka Tunggal lka, bagaimana indahnya perbedaan dalam keberagaman bagi masyarakat luas di Negara Kesatuan Republik Indonesia (NKRI). Destinasi yang akan ditawarkan antara lain Makam Kebangsaan yakni salah satu pemakaman umum yang terbuka bagi semua warga yang berbeda agamanya, baik Islam, Kriten,Katholik, Hindu dan Buda, yang tidak hanya Konghucu. Terdapat masjid yang berdampingan dengan Gereja. Awalnya terdapat Museum Kebangsaan, yang memang belum menggambarkan keunikan, kekhasan kebangsaannya, namun saat ini sudah dibongkar dan beralih menjadi Puskesmas. Destinasi lain dalam bentuk tradisi lokal, biasanya diselenggarakan pada bukan Syuro, yang telah menjadi tradisi penting dalam budaya Jawa (Riky,2010) seperti bersih desa yang dipusatkan di makam Mbah Pande yang diyakini masyarakat sebagai tokoh yang menjadi cikal bakal dusun Pandean, juga event "Tumpeng sewu"yang mampu menarik minat pengunjung dari luar desa Wonorejo. Destinasi alam juga tidak kalam menarik, pantai perengan yang sudah mulai dibenahi, hutan dan sebagainya. 
Hasil penelitian menunjukkan bahwa desa Wonorejo memiliki potensi untuk dijadikan komoditas wisata unggulan (Untari, 2018) demikian juga hasil PKM-M menunjukkan bahwa potensi wisata yang dimiliki desa Wonorejo cukup banyak, yang jika dikembangkan akan menjadi desa imbas dari wisata Baluran (Wantoro. 2018). Memasuki gerbang desa sudah terpampang nama Desa Wonorejo sebagai desa Kebangsaan , diresmikan Kabupaten Situbondo, Jawa Timur pada hari Sabtu, 2 Mei 2015.

\section{METODE}

Metode pelaksanaan pengabdian kepada masyarakat ini adalah metode partisipatif, dengan menekankan pada keikutsertaan penuh dari kelompok sasaran dalam proses pendampingan, bukan metode ceramah. Subyek sasaran mendorong untuk mencari, menemukan dan memperoleh pengetahuan/ketrampilan yang dibutuhkan. Dengan demikian dilakukan perubahan paradigma dalam pelaksanaan pengabdian pada masyarakat kali ini, bukan Tim pelaksana memberikan kepada desa dalam mengembangkan desa wisata, namun apa yang dibutuhkan desa untuk dikembangkan dan pendampingan dalam mengembangkan desa wista kebangsaan. Dengan berangkat dari kebutuhan desa, maka diharapkan akan ada keberlanjutan pembangunan dimasa yang akan datang (sustanable development). Artinya manakala kegiatan pengabdian pada masyarakat sudah selesai, masyarakat akan dapat melanjutkan kegiatan membangun desa wisata secara mandiri.

Strategi pelaksanaan yang dilakukan sebagai berikut: Tahap Observasi awal. Tahap observasi awal dilakukan observasi awal Tanggal 26 Juni 2019 di desa mitra yang menjadi sasaran pengabdian pada masyarakat. Pada kegiatan awal ketua tim pelaksana menghadap kepala desa untuk menyampaikan program kegiatan yang akan dilaksanakan, serta menyampaikan surat tugas dari UM; Tahap Sosialisasi Program Kegiatan, pada tahap ini Tim pengabdian melakukan diskusi dengan aparatur desa untuk menyampaikan gagasan dan kegiatan pengabdian; Tahap Fasilitasi PKK dan karang Taruna, pada tahap ini dilakukan fasilitasi 26-28 Juli 2019 yakni kegiatan memberikan wawasan bagi anggota dan kader PKK dan para pengurus dan anggota Karang Taruna akan peran penting masing-masing organisasi kemasyarakat dalam membangun desa wisata; Tahap Pengembangan Kerjasama, pada tahap ini dilaksanakan dengan membuat kesepahaman tertulis untuk melaksanakan kerjasama antara pemerintah desa Wonorejo dengan Universitas Negeri Malang. Nota kesepahaman sudah dibuat saat pelaksanaan PKM-M yang dilakukan Wantoro, Ikrima dan Mery tahun 2018. Pengembangan kerjasama hakekatnya sebagai pewujudan untuk saling bekerjasama antara desa Wonorejo dengan FIS terkait pengembangan desa wisata dengan fasilitasi melalui kegiatan Sarasehan Kebangsaan; Tahap Pendampingan, Tahap pendampingan dilakukan pada tanggal 8-9 Agustus 2019, tanggal 30 dan 31 Agustus 2019. Pada tahap ini dilaksanakan pelatihan untuk membuat cindera mata, nara sumber dari Universitas Negeri Malang, Bapak Deryan, selain pakar dibilang pembuatan merchendice/cindera mata juga pengusaha sablon. Pada tahap ini masih diberikan informasi dasar bagaiman peralatan, kebutuhan yang diperlukan untuk membuat cindera mata, bagaimana menghitung harga satuan, berapa ongkos produksi dan berapa mereka harus menjual satuannya. Tahap monitoring dan evaluasi dilakukan, pada tanggal 13 Oktober 2019 dilaksanakan bersama tim dari LP2M untuk mendapatkan testimoni dan umpan balik pelaksanaan pengabdian sekaligus melihat output dari pelaksanaan kegiatan yang dapat digambarkan pada gambar bagan 1 . 


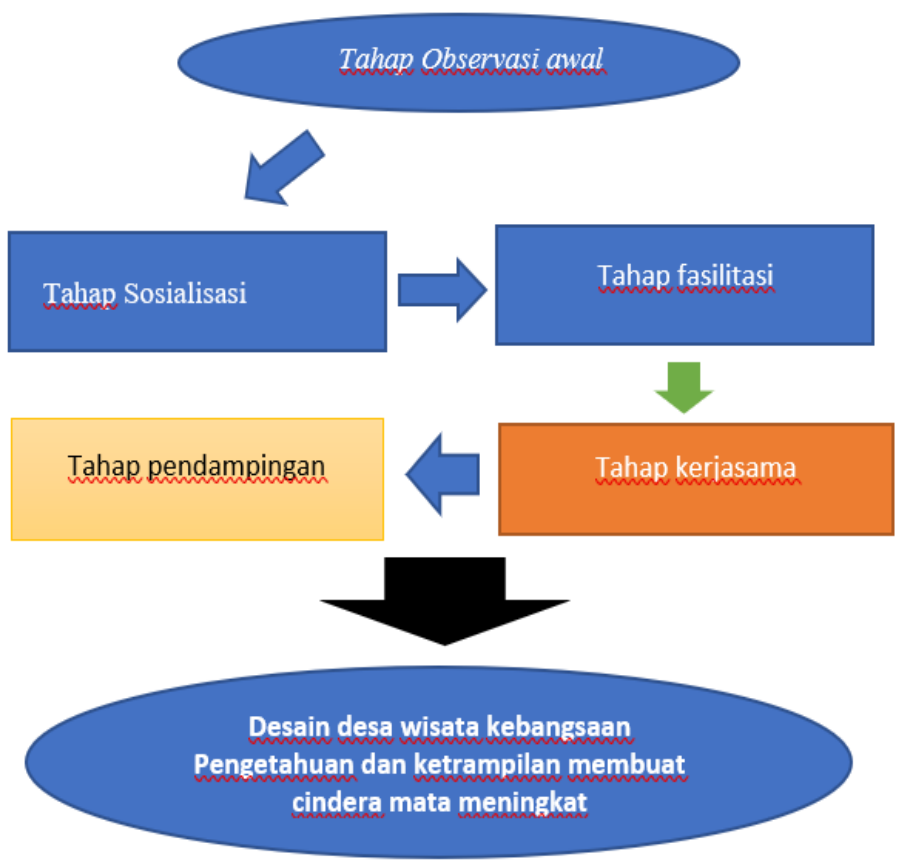

Gambar 1 Keseluruhan tahapan pelaksanaan pengabdian

\section{HASIL DAN PEMBAHASAN}

Prioritas pengembangan potensi wisata berdasarkan hasil sarasehan dan diskusi kelompok terfokus yang diselenggarakan dengan elit desa, menunjukkan potensi alam menjadi prioritas yang akan dikembangkan sebagai destinasi wisata unggulan desa wisata kebangsaan. Adapun potensi wista tersebut meliputi: (a) Potensi wisata alam, Potensi wisata alam yang diprioritaskan akan dikembangkan yakni pantai Parengan yang telah mulai dibenahi dengan melengkapi beberapa fasilitas umum, seperti mushola, toilet dan ruko yang menjual makanan dan minuman. Partai Perengan dapat menjadi andalan yang dikembangkan, karena memiliki daya tarik yang jika dipercantik menjadi destinasi wisata yang menarik; (b) Potensi wisata sejarah/religi, Potensi wisata yang menjadi unggulan yang dipilih untuk dikembangkan adalah wisata sejarah/religi. Wisata sejarah/religi ini berupa situs sejarah berupa makam mbah pande, makam mbah Jenun yang dipandang sebagai makam para pendiri dusun Pandean ataupun cikal bakan desa Wonorejo. Saat ini potensi wisata ini masih digarap secara sederhana, yang keramaiannya saat bulan Suro, dimana secara tradisi dilaksanakan upacara yang berpusat pada kedua makam tersebut; (c) Potensi wisata budaya, Potensi wisata budaya dalam bentuk even Tumpeng Sewu yang diselenggarakan tanggal 10 Suro (Muharam). Tumpeng sewu menjadi daya tarik bagi pengunjung desa wisata kebangsaan karena kirab budaya ini mengandung keunikan yang menggabarkan ke khasan masyarakat Wonorejo yang multikultural. Tidak hanya keterlibatan masyarakat lintas agama, suku, golongan. Juga tata cara doa yang dilakukan dengan cara Islam, Kristen, Katolik, Hindu dan Buda. Hal ini sesuai dengan pandangan Rizky (2010) bahwa dalam masyarakat jawa masih terus berkembang tradisi suroan.

Pengembangan potensi wisata terpilih di desa Wonorejo diharapkan menjadi wisata minat khusus, sebagaimana dikemukakan Priyanto (2016) bahwa pariwisata minat khusus wisatawan berkecederungan lebih menghargai lingkungan, alam, budaya dan atraksi secara spesial. Sedangkan Pascariu. Gabriela Carmen dan Dragan Gabriela (2006) menjelaskan bahwa salah satu sumber daya yang penting dalam pariwisata adalah suasana dan lingkungan umum (pemandangan, cuaca, sikap, 
perilaku). Hal ini sesuai dengan pilihan pemerintah desa dan masyarakat dalam mengembangkan potensi wisata yang ada di lingkungan desanya.

\section{Pengembangan kerjasama UM, Swasta dan Pemerintahan Desa}

Pengembangan kerjasama antara PT yakni UM dengan Pemdes Wonorejo. Berdasarkan dibuat melalui Nota Kesepahaman, sedangkan dengan swasta tanpa dokumen tertulis. Wujud pelaksanaan nota kesepahaman dalam bentuk peran masing-masing aktor atau pelaku kerjasama sebagai berikut: (a) Peran Pemerintah desa, Peran Pemerintah Desa Wonorejo adalah dengan membuat rencana program pembangunan desa wisata kebangsaan. Dalam kerjasama ini pemerintah desa memberikan ijin penyelenggaraan pengabdian kepalda masyarakat, menyediakan tempat, menyiapkan sumber daya manusia yang akan diberdayakan, memfasilitasi terselenggaranya kegiatan pendampingan; (b) Peran Perguruan Tinggi, Peran perguruan tinggi dalam hal ini Universitas Negeri Malang (UM) melalui kegiatan penelitian dan pengabdian pada masyarakat yang tahu 2019 ini dilaksanakan dengan berbagai kegiatan yakni sosialisasi, fasilitasi, sarasehan dengan elit dan pendampingan serta pemberian bantuan alat sablon untuk dipergunakan karang Taruna dalam memproduksi sablon sebagai cinderamata khas Wonorejo Kebangsaan dan yang penting adalah mencarikan mitra bagi pemasaran hasil produksi masyarakat; (c) Peran Swasta, Peran Swasta dalam hal ini pengusaha desa, koperasi taman nasional Baluran untuk melakukan pendampingan dalam mendesain produk cinderamata khas baluran yang dapat dipasarkan di lingkungan Taman Nasioal Baluran. Pihak pengusaha desa antara lain pemilik home stay juga menyatakan kesediannya untuk mendapat titipan cinderamata karya wanita dan pemuda untuk dipasarkan pada turis yang menginapa.

Gambaran relasi triple helix telah dijalin dalam pengembangan wisata desa kebangsaan, meskipun belum menggambarkan jalinan secara formal. Hal ini bertentangan dengan prinsip kemitraan yang menuntut adanya kesepakatan tertulis (Etzkowitz and Leydesdorff, 1995). Gambaran relasi tersebut sebagai gambar berikut:

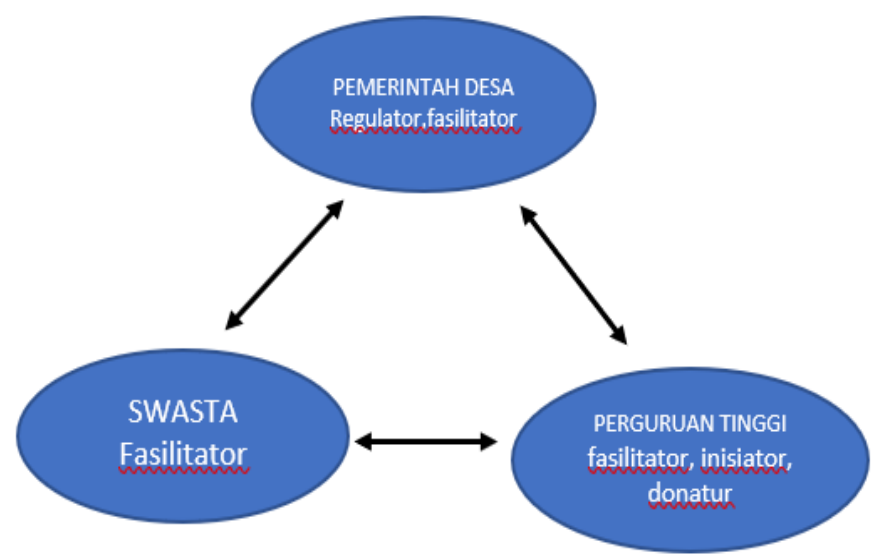

Gambar 2. Relasi Triple helix

Gambaran kerjasama antara pemerintah desa, UM dan pengusaha swasta belum diikat oleh nota kesepahaman, hanya antara pemerintah desa Wonorejo dan Fakultas IImu Sosial telah ditanda tangani antara Kepala Desa Wonorejo Sumarto Adi dan dekan FIS Prof. Dr. Sumarmi.M.Pd. Sedangkan dengan swasta belum dilaksanakan secara tertulis, namun berdasarkan pembicaraan pada saat pendampingan, Pak Tri mewakili swsata menyatakan, jika diperlukan ke depan akan dibuat nota kesepahaman agar jelas hak dan kewajiban masing-masing pihak. Triple helix ini memiliki manfaat bagi kepentingan masyarakat inilah yang merupakan hal penting dalam penyelenggaraan kemitraan (Bwana,2015), sedangkan Gabriela Carmen dan Dragan Gabriela (2006) menjelaskan salah satu sumber daya dalam pariwisata adanya aktor publik dan swasta yang terlibat atau mungkin terlibat dalam pengembangan wisata. 


\section{Pendampingan Karang Taruna dan PKK}

Pengabdian pada masyarakat ini dilakukan dengan melaksanakan pendampingan, dengan sasaran wanita dan pemuda. Selain berutujuan untuk memberikan pengetahuan juga keterampilan dasar.

\section{Pendampingan pada PKK}

Pendampingan pada kader PKK, dilakukan dengan memberikan informasi tentang kepariwisataan, menghasilkan cinderamata sederhana dari koran. Berdasarkan informasi awal sudah banyak kader PKK yang mengikuti pelatihan, seperti pembuatan bunga dari tas plastik (kresek) yang hasil keterampilan tersebut dapat dilihat di depan rumah hampir seluruh penduduk Desa Wonorejo. Pembuatan batik yang dikenal dengan ecogreen. Sedangkan pembuatan cinderamata belum pernah diberikan. Materi pendampingan selain pengetahuan tentang kepariwisataan, juga pengetahuan pentingnya cinderamata nagi desa wisata, praktik pembuatan.gambar kegiatan sebagai berikut:

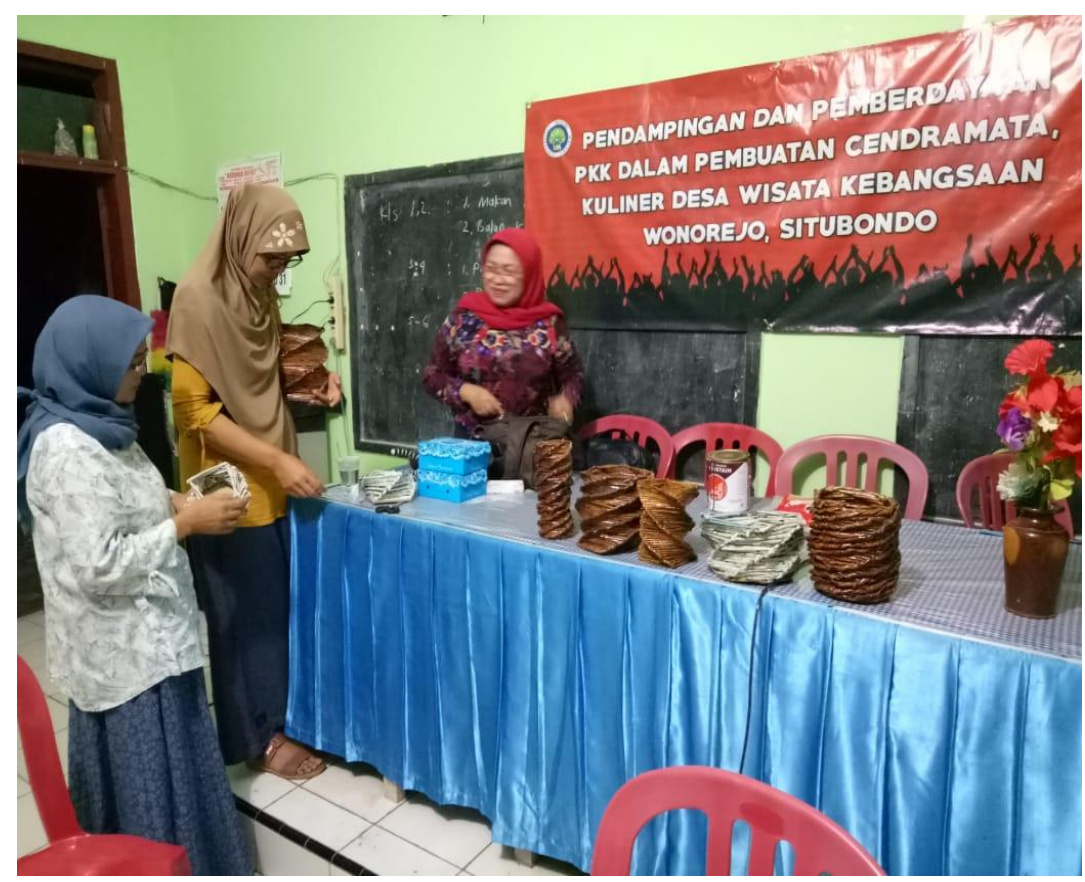

Gambar 3. Pendampingan pada PKK membuat keterampilan dari koran bekas

Hasil wawancara mendalam menunjukkan bahwa bentuk pengetahuan yang dibutuhkan kelompok PKKuntuk mewujudkan Desa wisata kebangsaan adalah penyuluhan mengenai pentingnya cinderamata bagi suatu desa wisata, cara pemanfaatan koran bekas untuk cinderamata, pelatihan pembuatan kerajinan tangan dari koran bekas, Hal ini sejalan dengan peserta pelatihan sablon menyatakan bahwa berdasarkan hasil wawancara pada peserta pendampingan mengharapkan adanya penyuluhan, dan pendampingan dan yang terpenting adalah pemasaran produk.

\section{Pendampingan pada Karang Taruna}

Pendampingan pada Karang Taruna dilaksanakan dengan kaos sablon yang mengandung ikon "WOKE"Wonorejo Kebangsaan. Sasaran pendampingan adalah para kader Karang taruna yang diharapkan dapat mengembangkan produk unggul untuk menunjang pengembangan desa wisata kebangsaam. Materi yang disampaikan selain peralatan sablon, fungsi masing-masing peralatan, desain kaos, dan pensablonan, pembersihan dan manajemen dana untuk usaha sablon, bisa dilihat pada gambar 4 dan 5 . 


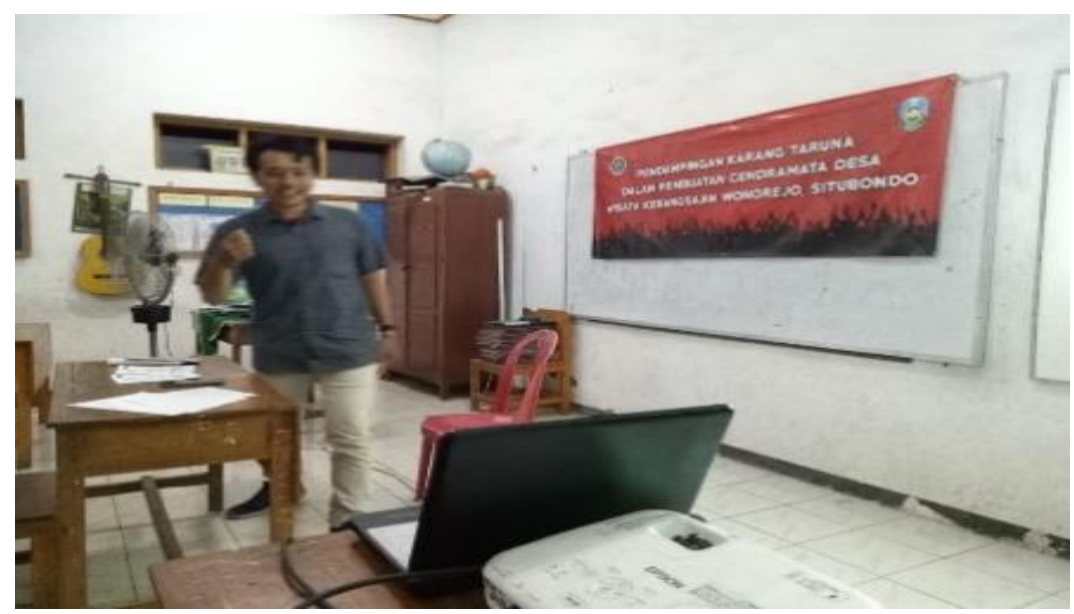

Gambar 4 Pendampingan pada Karang Taruna keterampilan sablón

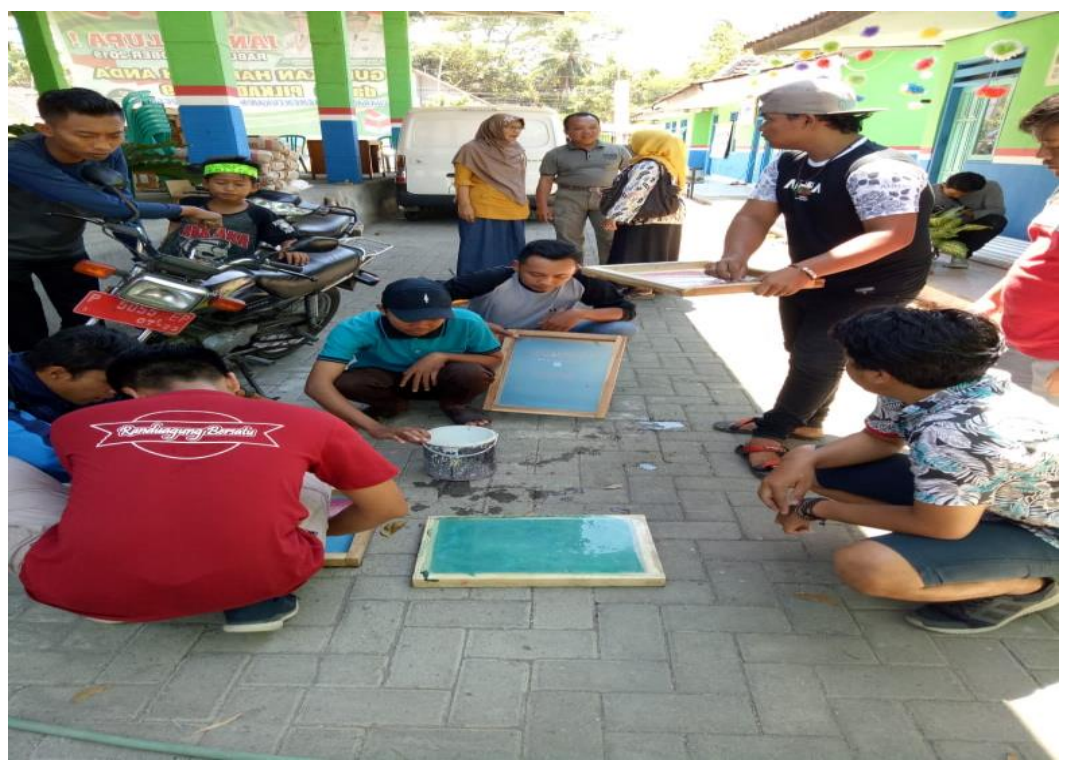

Gambar 5 Pelatihan membersihkan scanner

Pendampingan untuk kader PKK dan Karang Taruna pada hakekatnya dimaksudkan untuk memberdayakan sumberdaya masyarakat. Hal ini sesuai dengan pendapat Dewi yang menyatakan bahwa pembangunan berbasis masyarakat (community based tourism-CBT) merupakan model pembangunan yang memberikan peluang yang sebesar-besarnya kepada masyarakat pedesaan untuk berpartisipasi dalam pembangunan pariwisata. CBT merupakan sebuah kegiatan pembangunan pariwisata yang dilakukan sepenuhnya oleh masyarakat ( Dewi. 2013). Sedangkan Kurniasari (2013) menyatakan diperlukan partisipasi karang taruna untuk mengembangkan kreativitas generasi muda, yang pada giliranya akan berdampak positif bagi kemajuan pembangunan desa wisata kebangsaan (Egbali.Naser.2010).

\section{KESIMPULAN}

Berdasarkan paparan di atas kegiatan pengabdian pada masyarakat dapat disimpulkan bahwa potensi wisata yang menjadi prioritas akan dikembangkan oleh Pemerintah Desa Wonorejo potensi wisata alam yakni Pantai Pandean, potensi wisata sejarah/religi yakni makam Mbah Pande, Mbah Jenun serta budaya yakni even tumpeng sewu, karena dipandang potensi ini lebih mudah dikembangkan serta telah menjadi perhatian publik, dan berhasil mendatangkan pengunjung. 
Kerjasama antara Pemerintah Desa Wonorejo, UM dan Pengusaha lokal telah dirintis dengan masing-masing peran strategis dalam mendukung pengembangan desa wisata kebangsaan Wonorejo. Pemerintah Desa Wonorejo sebagai regulator dan fasilitator, donatur. UM sebagai fasilitator, pendamping dan donatur. Pengusaha lokal sebagai pendamping dan pemasaran hasil produk karang taruna dan PKK.

Kegiatan pendampingan ditujukan pada kader PKK dan Karang Taruna, dengan memberikan informasi kepariwisataan, pengetahuan tentang pemanfaatan koran bekas untuk souvenir atau cinderamata, dan pembuatannya. Untuk Karang Taruna diberikan pengetahuan tentang peralatan sablon, cara mendesain cinderamata, cara pembuatan kaos dan manajemen keuangan usaha sablon.

\section{DAFTAR PUSTAKA}

Bwana. 2015. Seizing An Opportunity Of A Public-Private Partnership Initiative For Agritourism Development As A Strategy For Poverty Reduction In Kisumu, Kenya. International Journal of Humanities and Social Science Invention ISSN (Online): 2319 - 7722,ISSN (Print): 2319- 7714 www.ijhssi.org //Volume 4 Issue 10 || October. 2015 || PP.52-64. Diakses 2 Agustus 2018

Ciolac R. et. al./Scientific. Papers: Animal Science and Biotechnologies, 2013, 46 (2)

Dewi. Made Heny Urmila. 2013. Pengembangan Desa Wisata Berbasis Partisipasi

Egbali, Naser. 2010. Effects of Positive and Negative ural Tourism : Case Study: Rural

Kurniasari.Dewi. 2013. Perang Organisasi Karang taruna dalam mengembangkan Kreativitas Generasi Muda di Desa Ngembarejo. Jurnal Civic Education 2 (2) tahun 2013. Http://jurnal.unnes.ac.id/sju/indek/ucej

Masyarakat Lokal Di Desa Wisata Jatiluwih Tabanan, Bali. Kawistara. VOLUME 3 No. 2, 17 Agustus 2013. Halaman 117-226. Diakses 19 Agustus 2018

Pascariu. Gabriela Carmen dan Dragan Gabriela.2006. The Role Of Public-Private Partnership In The Sustainable Development Of The Rural Tourist Destinations. https://www.researchgate.net/publication/23732128

Priyanto.2016. Pengembangan Potensi Desa Wisata Berbasis Budayatinjauan Terhadap Desa Wisata Di Jawa Tengah. Jurnal Vokasi Indonesia. Volume 4. Nomor1.Januari-Juni 2016

Ramona Ciolac, et all. 2013 Public-Private Partnerships On Rural Tourism Field In Europe An Innovation For Rural Development -Achievements And Proposals.

Riky Indonesia Kaya. 2010 Perayaan Satu Suro, Tradisi Malam Sakral Masyarakat Jawa. https://www.indonesiakaya.com/jelajah-indonesia/detail/perayaan-satu-suro-tradisi- malamsakral-masyarakat-jawa?

Semnan, Provincion. Journal of Geography and Regional Planning Vol. 4(2), pp. 63-76, February 2011 Available online at http://www.academicjournals.org/JGRP ISSN 2070-1845 @2011 Academic Journals

Untari. Sri,dkk.2018. Pola Kemitraan Antara Pemerintah-Masyarakat-Swasta Dalam Pengembangan Desa Wisata Sebagai Upaya Menumbuhkan Spirit Kewirausahaan, Pengembangan Aset Wisata Dan Cagar Budaya Di Jawa Timur. Laporan Penelitian Dana PNBP 2018. LP2M Universitas Negeri Malang

Utomo. Selamet Joko.dkk.2017. Strategi Pengembangan Desa Wisata Di Kecamatan Karangploso Kabupaten Malang. Neo-bis Volume 11, No.2, Desember 2017

Wantoro. M.2018. Woke! "Wonorejo Berkebangsaan" Rintisan Desa Bhineka Tunggal Ika Sebagai Wahana Edukasi Nilai-nilai Pancasila melalui Pendekatan PRA (Participatory Rural Appraisal) dalam Rangka Pencapaian Program Nawa Cita. Laporan PKM-M didanai. 